\title{
Density and Disasters: Economics of Urban Hazard Risk
}

\section{Somik V. Lall • Uwe Deichmann}

Today, 370 million people live in cities in earthquake prone areas and 310 million in cities with a high probability of tropical cyclones. By 2050 these numbers are likely to more than double, leading to a greater concentration of hazard risk in many of the world's cities. The authors discuss what sets hazard risk in urban areas apart, summarize estimates of valuation of hazard risk, and discuss implications for individual mitigation and public policy. The main conclusions are that urban agglomeration economies change the cost-benefit calculation of hazard mitigation; that good hazard management is first and foremost good general urban management; and that the public sector must perform better in promoting market-based risk reduction by generating and disseminating credible information on hazard risk in cities. JEL codes: Q54, R3, H41

Hurricane Katrina in 2005 caused close to US\$100 billion in direct damages in New Orleans. The January 2010 earthquake in Port-au-Prince resulted in more than 200,000 fatalities. These and other recent disasters in cities remind us of the large and perhaps growing risk that urban areas face from natural hazards. Storms, earthquakes, floods and tsunamis do not seek out cities. But when they do occur in an urban area, the large concentration of people and assets tends to increase their impacts. This concentration is the result of economic forces such as economies of scale and specialization in production (World Bank 2008). They generate agglomeration economies that further encourage urban growth up to a point where congestion costs start to dominate. The attraction of cities means that moving out of harm's way is not usually a feasible risk reduction strategy. The stakes-most clearly reflected in higher wages and productivity-are too high. 
Urban hazard risk cannot be eliminated, but it can be reduced. We argue that markets can provide incentives for private mitigation efforts and mechanisms for risk transfer. But there remains a significant role for economic policy and urban management to facilitate market based responses and to act when markets fail. Three areas are of particular importance. First, municipal governments must ensure good general urban management that helps reduce risk. This includes, for instance, managing land to exclude hazardous areas from development, maintaining drainage systems, ensuring the safety of public buildings, and providing effective first responder services. Second, public agencies need to facilitate private risk reduction efforts by creating and widely disseminating information about hazard risk. This generates broad awareness that helps individuals and firms to decide how much risk they are willing to accept. And it avoids information asymmetries, for instance, where private firms such as insurance companies collect but do not share such information. Third, urban governments may need to intervene selectively to address specific welfare impacts such as the disproportional risk faced by poor people when only hazard-prone land is affordable.

Throughout this paper we adopt the standard risk model used in the natural hazards community (see, for example, ISDR 2009). Risk of losses-mortality, injuries, or economic damages - is a function of the probability that a hazard event of a given magnitude will occur, exposure of people or assets, and vulnerability which includes factors that make it more or less likely that the exposed elements are affected. ${ }^{1}$ A hazard event turns into a natural disaster when it takes place in an area of high exposure and vulnerability.

The paper is organized in three main sections. First, we discuss why a separate treatment of urban hazard risk is warranted. We argue that the benefits of economic density in cities will continue to encourage concentration of people and assets at risk from natural hazards. This geographic concentration changes the range of options and priorities for dealing with natural hazard risk. Second, we survey past research and present new findings that show how hazard risk implicitly enters the cost-benefit calculations of firms and households. The evidence suggests that if information is available and land markets work well, natural hazard risk is priced into real estate markets. This encourages marketbased risk reduction. But it also means that poor people are attracted by lower land prices in hazard prone locations leading to disproportional risk exposure for low-income groups. Third, we discuss policy options for mitigating urban hazard risk. We distinguish between large scale collective measures to reduce risk and individual level risk mitigation. We also highlight the importance of good general urban management in reducing risk, and we argue for a much larger public sector role in creating and disseminating hazard related information that encourages market-based risk reduction approaches. 


\section{Why Urban Hazard Risk Is Different}

Why treat urban hazard risk separately from hazard risk in general? Many of the concepts and lessons relevant to hazard risk reduction apply generally-in rural, peri-urban and urban areas. But some issues are specific to cities. Most importantly, as they increase in size, more people and assets will be exposed to natural hazards in dense urban areas. This density, of people and economic activity, not only changes the risk equation, it can also change the economics of hazard risk reduction strategies. We first summarize what drives urban hazard risk, before discussing the implications of recent research in urban economics and economic geography for natural hazard risk in cities.

\section{Hazard Risk in Cities Is Large and Increasing}

Global disaster damage statistics are not classified by urban versus rural location. We therefore have no concrete empirical evidence as to whether natural hazard events have more severe impacts in urban areas as compared to rural areas. Despite this uncertainty, there are several factors that increase hazard risk in cities, including physical geography, land scarcity, externalities due to dense habitation, and rapidly rising exposure. Income growth that decreases vulnerability tends to be faster in cities and works in the opposite direction. A core message is that in a rapidly urbanizing developing world, the growth of population and economic assets in cities will likely lead to an increasing concentration of hazard risk in the urban areas of developing countries.

Geography. The interplay of economic and physical geography is one reason for high hazard risk in urban areas. Many cities have historically emerged at a location with good accessibility or favorable natural endowments such as a river crossing, a coastal location, or fertile volcanic soils. Those geographic settings are often associated with an increased probability of hazard events-floods, cyclones, and volcanic eruptions. Agriculture in most of southern Italy is difficult due to poor soil quality. An exception is the area around Mount Vesuvius near the city of Naples where rich volcanic soils have been farmed for centuries despite the risk of new eruptions. Globally an estimated 9 percent of the population lives within 100 kilometers of a historically active volcano, many in cities and with high concentrations in Southeast Asia-particularly in Indonesia and the Philippines-and Central America (Small and Naumann 2001). Similarly, low elevation coastal zones, many exposed to cyclones and storm surges, cover 2 percent of the world's land area but contain 10 percent of the world's population and 13 percent of the world's urban population (McGranahan, Balk, and Anderson 2007). 
Land Scarcity. Competition for land in urban areas is intense. City managers often exacerbate land scarcity by restricting high density development. The desire to live close to jobs and amenities means that even marginal city areas such as floodplains, areas with unstable soil, or steep slopes will be settled-often, though not always, by poor people. In Santo Domingo's largest slum, 45 percent of houses located near a river are flooded when it rains (Fay, Ghesquiere, and Solo 2003; Fay and others 2001). Housing prices reflect this risk with the poorest living in the lowest quality housing in the most at-risk areas. In cities such as Caracas or Rio de Janeiro, poor families occupy steeply sloped ground which is prone to landslides. This sorting process, with low income households and squatters occupying the most hazardous urban land, is not static. Detailed data for Cali, Colombia, show that localized hotspots of small scale disaster events change location as inner-city neighborhoods gentrify, governments improve hazard management, and new informal settlements emerge at the periphery (ISDR 2009).

Externalities. Land scarcity leads to higher land prices and therefore to higher density occupation. Larger building sizes in cities may increase damages and loss of life in severe earthquakes especially where building standards are lax. The collapse of larger buildings in dense urban areas can cause neighboring buildings or critical supply infrastructure to be damaged even if they otherwise withstood the event (Kunreuther and Roth 1998; Nakagawa, Saito, and Yamaga 2007). These spillovers or externalities are absent in more sparsely populated rural areas where damages to smaller sized and dispersed dwellings will cause less or no collateral damage.

Exposure. The main reason why urban risk is large and increasing is the rise in exposure. Urban populations are growing in practically all developing countries. About half of this increase is natural growth, that is fertility of urban dwellers (Montgomery 2009). The remaining growth is due to urban expansion and migration, which reduces the national share of rural residents except where rural fertility is vastly larger.

The latest UN urban population estimates suggest that, globally, urban population exceeded rural population for the first time in 2008 (UN 2008). In less developed regions, this threshold is expected to be reached by 2019. Although we can only speculate about the global distribution of disaster damage in cities today and in the future, newly available, geographically referenced data yield estimates of urban exposure to natural hazards. We prepared city-specific population projections for 1970 to 2050 and combined these with a comprehensive database of tropical cyclone and earthquake events during 1975-2007 (ISDR 2009; see World Bank 2009). Cities are included if their population exceeded 100,000 in a 
given year. There were about 3,700 such cities in 2000. By 2050, there could be 6,400.

Population in large cities exposed to cyclones is estimated to increase from 310 to 680 million between 2000 and 2050. These estimates assume that cyclone frequencies, severity, and geographic distribution over this period will be similar to the 1975 to 2007 period. Climate change will likely affect sea surface temperature and other factors determining cyclone patterns, but the precise nature of these effects is still vigorously debated in the scientific literature, although a decrease in cyclone risk is unlikely. As seismic activity is more stable over time, these caveats do not apply for earthquakes. Our estimates suggest that urban population exposed in areas with a significant probability of a major earthquake increases from 370 million in 2000 to 870 million in 2050. In both cases, this increase in urban hazard exposure is likely not a net increase in total exposure (rural + urban) since some share of these additional urban residents will have come from hazard affected rural areas.

The largest anticipated urban population exposed to cyclones is in south Asia, where it is estimated that 246 million residents of large cities will be living in areas affected by severe storms by 2050 (Figure 1). OECD countries and the East Asia and Pacific region each will have about 160 million urban residents exposed to cyclones. South Asia also experiences the second largest growth in urban

Figure 1. Population in Large Cities Exposed to Cyclones (1970-2050)

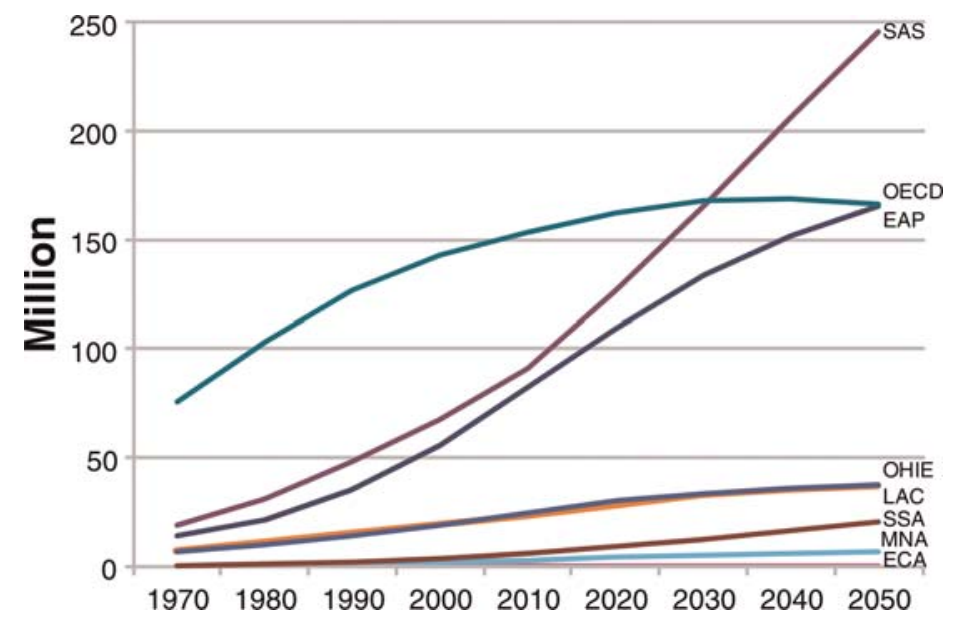

Notes: $\mathrm{EAP}=$ East Asia and Pacific, ECA = Europe and Central Asia, LAC = Latin America and Caribbean, $\mathrm{MNA}=$ Middle East and North Africa, $\mathrm{OECD}=$ Organisation for Economic Cooperation and Development, $\mathrm{OHIE}=$ Other High Income Economies, SAS = South Asia, SSA = Sub-Saharan Africa.

Source: World Bank (2009). 
Figure 2. Population in Large Cities Exposed to Earthquakes (1970-2050)

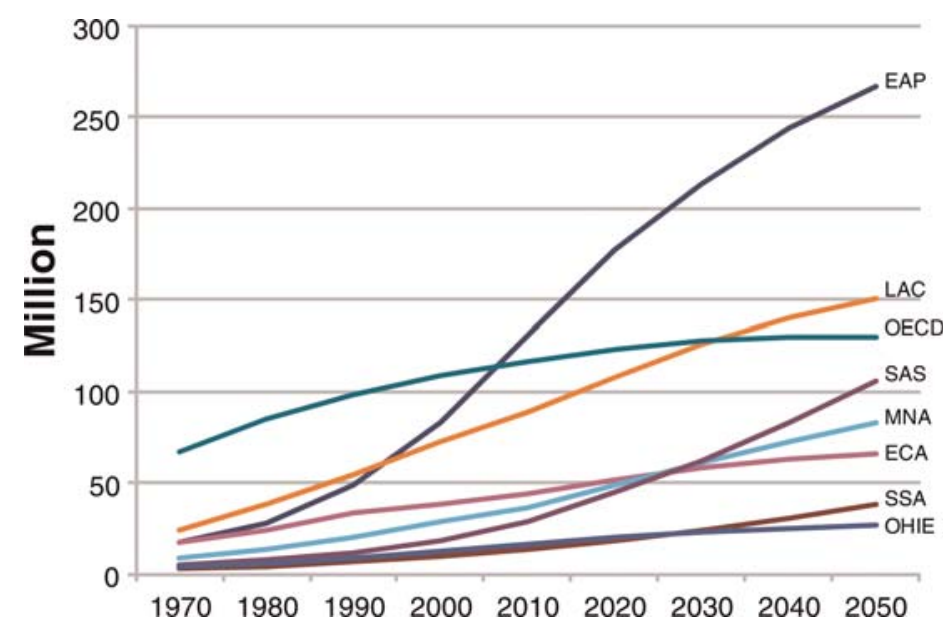

Notes: $\mathrm{EAP}=$ East Asia and Pacific, ECA = Europe and Central Asia, LAC = Latin America and Caribbean, MNA $=$ Middle East and North Africa, $\mathrm{OECD}=$ Organisation for Economic Cooperation and Development, $\mathrm{OHIE}=$ Other High Income Economies, SAS = South Asia, SSA = Sub-Saharan Africa.

Source: World Bank (2009).

cyclone exposure between 2000 and 2050 at about 2.6 percent per year. This is exceeded only by Sub-Saharan Africa's 3.5 percent, although that region's total exposure will remain relatively small at 21 million in 2050.

Urban exposure to earthquakes is expected to be largest in East Asia and the Pacific at 267 million in 2050 from 83 million in 2000 (Figure 2). Exposure is also high in Latin America and the Caribbean (150 million in 2050) and OECD countries (129 million in 2050). The fastest growth of urban earthquake exposure is expected to occur in South Asia (3.5 percent) followed by SubSaharan Africa (2.7 percent).

What applies to population, applies even more to economic assets and output. Cities are engines of growth and firms prefer to locate in urban centers with good access to labor markets, complementary inputs, and customers. Increasing returns and specialization raise productivity to levels not achievable in rural areas. Each urban unit of area therefore generates far greater output and hosts a larger stock of economic assets, public infrastructure, and private property. Estimates of GDP for cities are not widely available, except for a few countries and some of the larger world cities. These suggest that urban output per capita tends to be several times higher than in rural areas. Relative economic exposure to natural hazards will therefore be considerably higher in cities than in rural areas.

These exposure trends have profound implications for urban hazard risk profiles. With climate change, event probabilities may increase for hydro-meteorological 
hazards. Vulnerability - the characteristics of exposed assets or people that make them more or less likely to be damaged by a hazard event-may also increase initially as fast urban growth leads to rising slum populations in sub-standard housing. But the main driver of hazard risk in urban areas today and over the next few decades will simply be the greater accumulation of exposure, likely exceeding the contribution of climate change by some margin (see for example ISDR 2009).

Some Factors May Reduce Urban Risk. Urban areas also have characteristics that mitigate hazard impacts. Firstly, urbanization tends to be associated with increasing incomes and better education. These generally reduce damages (Kahn 2005; ISDR 2009). Loss of life is much lower in rich countries. Economic damages tend to be larger, but when measured as a share of exposed wealth, they are smaller than in poor countries. Higher incomes reduce both dimensions of vulnerability. Damages will be lower because of better quality housing, higher affordability of mitigation, and better institutions that lead to enforcement of rules and regulations aimed at reducing impacts. And wealthier households have greater coping capacity, for instance, the means to rebuild damaged structures quickly. Secondly, there are scale economies in risk mitigation. For example, risk control measures benefit more people, enforcement of standards is cheaper, and the cost of first responder services is shared by a larger population. Finally, urban areas may be favored in risk reduction expenditures, since most decisionmakers and media reside in cities. Urban hazard impacts receive more attention and recovery efforts receive more resources. Whether, or to what extent, this "urban bias" exists is an interesting question for empirical evaluation.

\section{Economic Geography Changes the Risk Equation}

The defining characteristic of cities is the concentration of people and economic assets in a relatively small space. Globally, a conservative estimate of economic concentration or density suggests that half of worldwide GDP is produced in just 1.5 percent of the world's land, almost all of it in cities (World Bank 2008). This area is home to about one-sixth of the world's population.

When cities function efficiently, they attract firms in industries and services that value agglomeration economies. In fact, these economies are the reason that cities exist (Duranton and Puga 2004). They can occur within a given sector, when firms in the same industry locate in a metropolitan area to enjoy access to specialized suppliers or expertise that could not be supported by lesser concentrations. Or they can occur across industries, as when firms from different industries benefit from collocating because the diversity of their skills and experiences encourages innovation. Agglomeration economies can be in consumption as well as production. Large cities attract residents because of generally better service 
provision and a wider variety of restaurants, museums, and other forms of entertainment. Empirical research confirms that these economies are substantial. Average productivity increases by 4 to 20 percent with each doubling of metropolitan population, and these productivity effects are particularly pronounced in certain industries (Rosenthal and Strange 2004).

Agglomeration economies change how households and firms respond to natural hazard risk. Most hazards have relatively low probabilities. So cities in hazard zones remain attractive even if the consequences of a hazard event would be large. Well-known earthquake hotspots like San Francisco, Istanbul, or Tehran have not seen a decline in population. Even when the frequency of events is high, many cities have natural advantages or accumulated infrastructure that ensure their continued attraction. In the last 30 years, the resort city of Cancun in Mexico has been hit by a hurricane about once every three years, including four category 4 or 5 storms (ISDR 2009). This has not diminished its status as one of the most visited holiday destinations in North America. If cities deliver economies of scale and agglomeration, the stakes of being physically close to economic density will be high enough for people not to be deterred by hazard risk. Rather than move out, mitigation (for example retrofitting buildings) and risk transfer (for example insurance) will be the main responses to risk.

But if cities are inefficient - either due to weak institutions or bad policies- the economic gains from agglomeration will be low, making these locations less attractive to households and business owners. In those cases, hazard risk may further diminish growth prospects. A simple analysis of global cities suggests that population growth between 1960 and 2000 is slower in low income country cities at risk from earthquakes. Middle income and high income country cities do not exhibit any statistical differences in growth rates (Figure 3). Similar patterns are found for landslide risk.

Figure 3. Population Growth Rates for Cities with Populations Over 100,000, Combined with Hazard Distribution
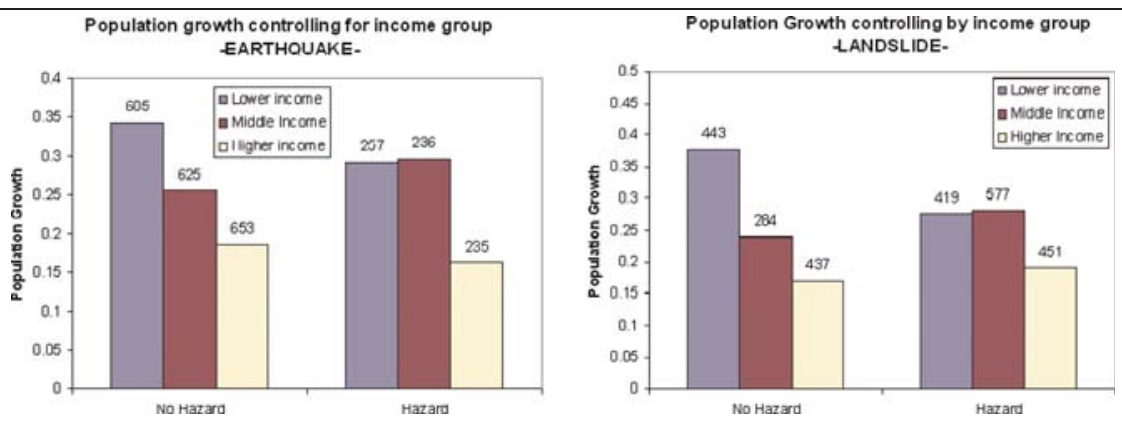

Source: Authors' calculation based on Henderson (2003); Dilley and others (2005). 
This section has summarized the broad patterns and trends that shape hazard risk in cities across the world. In the following section we will discuss how hazard risk in individual cities is reflected in real estate prices and how it shapes the distribution of urban population by income.

\section{The Valuation and Distribution of Hazard Risk in Cities}

Although hazard risk has a relatively small impact on city growth globally-other factors such as economic geography dominate-we expect that differences in risk within a city will have an impact. Evidence from empirical research is scarce but suggests that natural hazard risk is priced into property values if risk awareness is high. Much of the empirical evidence is based on estimation of hedonic models, where land and housing prices reflect the value of a property's physical characteristics such as size, and the characteristics of its neighborhood (Rosen 1974). The present value of a property is thus the capitalized sum of benefits derived from it, including the relative safety or risk level of its location.

Flood zone disclosure is mandatory in some areas of the United States, such as parts of North Carolina, so buyers are aware of flood risk before buying a property. Using a hedonic property price model, Bin, Brown Kruse and Landry (2008) find that the property market reflects geographic differentials in flood risk, reducing property values on average by 7.3 percent. This property price discount is about equal to the flood insurance premium for homes in the flood zone. Bin and Polasky (2004) examine the effect of Hurricane Floyd (September 1999) on property values in North Carolina. The storm affected 2 million people and damaged property worth $\$ 6$ billion. Most properties did not have flood insurance before the hurricane but the event increased the awareness of flood hazards and houses located on the floodplain faced a price reduction of 4 to 12 percent. These price reductions were about 8 percent higher than the capitalized value of insurance premiums, suggesting the existence of noninsurable costs associated with flooding.

In Istanbul property values in 2000 were found to be lower near the seismic fault lines in the Sea of Marmara compared to those further away (Onder, Dokmeci, and Keskin 2004). In contrast, proximity to the fault line had no impact on property values when data from 1995 were used for the analysis. Presumably information on distance from fault lines influenced property values as households became more conscious of hazard risk only after the Kocaeli earthquake in 1999. Awareness of the consequences, especially recent memory of a hazard event, therefore clearly influences housing market response.

New evidence for Bogota compiled for the World Bank-UN Assessment on the Economics of Disaster Risk Reduction confirms that risk levels influence home 
prices (Atuesta and others forthcoming). Some 800,000 buildings in Bogota were matched on a range of characteristics such as size, construction quality, distance from the city center, and whether residential, commercial, or industrial. Because the only visible difference among comparable properties is their level of hazard risk, this allowed assessing whether property values are lower in riskier areas. In general, the analysis found that property prices rise with increasing distance to the city's areas of highest seismic risk, such as La Picota Oriental, San Juan Bautista, and La Arbolada Sur. For example properties in the riskiest decile are valued 7 to 10 percent less than similar properties in the next riskiest decile. At the extreme, comparable properties are on average twice as expensive in the areas that are furthest from places where earthquake impacts are predicted to be highest.

If risk is reflected in housing prices, then private investment in mitigation should also be capitalized into property values. In principle, home owners should be able to recover investments in mitigation, such as earthquake proofing structures, through increases in property prices. Evidence from Tokyo, Tehran, and Bogota confirms this. Nakagawa, Saito, and Yamaga (2007) use a 1998 hazard map of the Tokyo Metropolitan Area to examine the extent to which housing rents reflect earthquake risk as well as earthquake-resistant materials used in construction. The study exploits the fact that the building codes were amended in 1981 to enhance the earthquake-resistant quality of structures. Any building constructed after 1981 needed to conform to the new standard. The study finds that the rent of houses built prior to 1981 is discounted more substantially in risky areas than that of houses built after 1981.

In Tehran, Willis and Asgary (1997) interview real estate agents to examine the capitalization of investments in earthquake risk reduction on property values and assess if home buyers are willing to pay for improvements incorporated into a house. The estimates suggest significant price differences between earthquakeresistant and nonresistant houses, across all districts in the city. The adoption of such measures in Tehran is limited, however, which may be due to inadequate public information about earthquake risks as well as affordability.

More general evidence comes from an analysis of global office rents. Investors need to balance hazard risk with gains from economic density. Gomez-Ibañez and Ruiz Nuñez (2006) constructed a dataset of central business district office rents for 155 cities around the world in 2005 to identify cities where rents seem elevated or depressed by poor land use or infrastructure policies. The dataset also includes information on many factors that determine the supply and demand for central office space, such as construction wage rates, steel and cement prices, geographic constraints, metropolitan populations, and incomes. We combined this dataset with hazard risk information from a global assessment (Dilley and others 2005) and examined whether city demand-as reflected in office rents-is 
sensitive to risk from natural hazards. The results from this analysis can only be considered as crude indicators of correlation, not precise magnitudes of causal relationships. Controlling for factors such as construction wage rates, vacancy rates, urban population numbers and density, as well as environmental quality factors, we find that being in an earthquake zone significantly lowers office rents. A measure of the magnitude of earthquake risk yields the same result. Similar regressions for floods and cyclones did not generate statistically significant correlations.

Changes in home prices in response to hazard risk are a manifestation of household's coping strategies. Households accept higher risk in return for lower housing costs. This trade-off is not always a free choice. Hollywood stars may choose to reside in the wildfire-prone hills surrounding Los Angeles to enjoy the stunning views. But poorer households may locate in undesirable areas that they can afford because alternative locations in safe but distant neighborhoods incur high commuting costs. This sorting of households is well-known in the environmental equity literature (see for example Bowen 2002). There is less formal evidence in the natural hazard context, and reliable identification of causes and impacts is difficult in both fields.

When facing risk from natural hazards, individuals can respond in three main ways: they can move out of harm's way; they can self-protect, for instance by retro-fitting their properties; or they can transfer risk to property, though not to life, where insurance markets function. Following Hurricane Andrew in 1992one of the largest natural disasters to affect the United States - the economic status of households explained most of the differences in their responses (Smith and others 2006). As property prices in the worst affected areas fell the most, low income households responded by moving into low-rent housing offered in these locations. Middle income households moved away from such areas to avoid risk. And the wealthy, for whom insurance and self-protection are the most affordable, did not change where they lived.

In developing countries, urban risk profiles are further influenced by the strong divide between formal and informal land markets. While formal developments may respect land use regulations, informal settlements spring up on any parcel available, often in hazard prone locations that are consciously avoided by formal builders. In Dhaka, for example, informal settlements are scattered throughout the metropolitan area. Many of these slums are in locations at risk from flooding (World Bank 2005). In Bogotá, poor people face a disproportionately high burden of earthquake risk, as they sort into high density low rent properties, which are located in higher risk locations. On average the city's poor live in locations that have twice the seismic risk compared to where rich households are located.

A major reason why poor households in informal settlements are willing to accept substandard housing and higher risk is because they want to be physically 
integrated in the urban labor market. Evidence from Pune, India, shows that poor households prefer to live close to their workplace in centrally located slums rather than in better quality housing at a city's outskirts (Lall, Lundberg, and Shalizi 2008). Many of these slums are located on riverbanks that are prone to flooding or on hillsides. Slum residents are also willing to pay a premium to live with households sharing their language, religion, education levels, and length of tenure in the neighborhood-community structure and social capital are important. An assessment of the welfare impact of relocating slum dwellers from their current location to places in a city's periphery shows that relative to no intervention (allowing slum dwellers to be in their current location, with the same service levels and housing conditions), upgrading services in situ is the only policy intervention examined which increases welfare of these slum dwellers. This has implications if relocation of low-income households out of hazardous areas is the only viable option. Communities should then ideally be resettled as a group to preserve social structures and with similar access to job opportunities, for example by providing affordable public transportation.

The challenges of informal development in hazardous locations are most severe when local governments have weak administrative capacity. This is often the case in expanding urban areas just outside the administrative city limits. In Dakar, Senegal, for example, the fastest population growth in the metropolitan region over the last 20 years happened in peri-urban areas. Forty percent of the population growth in these peri-urban areas occurred on high-risk land, a percentage almost twice that in rural and urban areas (Wang and others 2009). Why are peri-urban areas more vulnerable? These settlements are often unplanned due to a lack of development standards and land-use plans compounded by weak institutional structures. For instance, these essentially urban areas may still be governed by structures designed for rural administration. They therefore lack adequate infrastructure, have weak property rights, and may be located in areas initially avoided during early settlement because of environmental or hazard factors. Their attraction, as illustrated by the case of Dakar, is that they provide cheap and readily available land for a rapidly growing urban population. In many of the world's megacities, annual growth rates of population in peripheral urban areas are around 10 to 20 percent higher compared to areas near central business districts (Pelling 2003).

\section{Implications for Public Policy}

Hazard management is a task both for the public sector and for private households and firms. For the public sector, this includes ensuring the safety of municipal buildings and public urban infrastructure, encouraging and supporting 
private sector hazard risk reduction, and developing first response capacity. A considerable share of hazard risk stems from relatively small but frequent events which cause localized damage and few injuries or deaths (Bull-Kamanga and others 2003). An analysis of detailed records of 126,000 hazard events in Latin America showed that more than 99 percent of reported events caused less than 50 deaths or 500 destroyed houses (ISDR 2009). In aggregate, these accounted for 16.3 percent of total hazard related mortality and 51.3 percent of housing damage. The probability of larger events may or may not be predictable. Some cities in earthquake zones have generated seismic maps (for example liquefaction hazard maps showing where soils may become unstable). But seismic dynamics are so complex that the precise areas within the city where damage will occur cannot usually be pinpointed precisely. Furthermore there is no simple engineering fix that would remove the hazard from a particular area. Individual dwelling, unit level mitigation is therefore necessary everywhere in the general area of high ground-shaking probability. For other hazard types, like landslides and floods, potential risk areas can be more easily delineated. Households in the risk zone have limited options for protecting against these hazards individually. But some form of large, collective risk mitigation is sometimes feasible, such as levees or slope stabilization measures.

The following paragraphs discuss the role of public policies in urban hazard risk reduction in three main areas: (1) Ensuring good, routine urban management, including smart land use management and collecting and disseminating comprehensive information about hazard risk; (2) carefully assessing the benefits of large-scale collective disaster reduction infrastructure; and (3) encouraging mitigation efforts at the individual level.

\section{Urban Management}

Urban hazard risk reduction begins with everyday city management. Many standard public functions that appear unrelated to hazard risk management can affect exposure or vulnerability to natural hazards.

Maintenance of Public Services. Natural disasters are the man-made consequences of geophysical hazard events. This applies for large as much as for small-scale hazards. But smaller disasters can be more easily avoided. Good, routine urban management already reduces hazard risk considerably. By mainstreaming hazard risk reduction in everyday urban planning and management, damages can be avoided early on. For instance floods in developing country cities are often the consequence of insufficient maintenance of drainage systems. In South Asia, monsoon rains often encounter drainage ditches that are used as garbage dumps, because regular refuse collection is insufficient. Drains lose their function to 
transport runoff away from settlements. For example Mumbai spends about 1 billion rupees ( $\$ 25$ million) per year on preparing for monsoon rains. Yet the 2005 monsoon caused 300 deaths. $^{2}$ Unchecked urban development that leaves too little porous green space further increases runoff and flood risk.

Smart Land Use Management. Land use planning is a core task of city government that shapes hazard risk. For risk reduction the main objective is to prevent development of hazard prone land. In fast growing cities land for new development is scarce. Poor people often cannot afford transport charges and need to locate close to city centers to have access to labor markets. They end up on the least desirable land, such as flood plains or steep and unstable slopes. To reduce settlement of these areas cities need to use a combination of regulation and incentives. Zoning enforcement must attempt to prevent settlement of the most risky areas. This is not easy since informal settlements can spring up overnight and once established are difficult to relocate. ${ }^{3}$ To absorb a growing population while excluding riskprone areas, cities need to ensure a supply of suitable land for new development. As these areas will be further from economic opportunities, land development must be accompanied by affordable transport services.

Increase Supply of Formal Housing in Safe Areas. In many countries, excessive land regulations have led to shortages in formal land supply in safe areas and driven up prices. This makes it difficult for many households to enter the formal land market. One frequently used land-use regulation is restriction of building heights, which leads to inefficient use of the most desirable land. These limits are imposed via restrictions on a structure's floor-area ratio (FAR), which equals the total floor area in the building divided by the lot size. Throughout the world, zoning regulations usually specify maximum FAR values in different parts of a city. But these FAR limits typically do not represent severe constraints on development, as they often roughly match the developer's preferences in a given location. In effect, FAR restrictions often "follow the market," providing a way for city planners to ensure that the character of development does not diverge greatly from the norm. But not all cities adapt regulations with such flexibility. In Mumbai, for instance, planners went against the grain of markets (World Bank 2008). FARs were introduced in 1964 and set at 4.5. Rather than raising the allowable density over time to accommodate urban growth, planners in Mumbai went the other way, lowering the index to 1.3 in 1991. These regulations hold Mumbai's buildings to only between a fifth and a tenth of the number of floors allowed in major cities in other countries. The city's topography should exhibit a high-density pattern similar to that in Hong Kong, China, but it is instead mostly a low-rise city outside the central business district. Space consumption averages 4 square meters, one-third of the level in Shanghai and less than one-fifth of that in 
Moscow. People still keep coming to Mumbai, but face skyrocketing housing prices and rapid slum formation.

Expand Property Rights. The literature on property rights provides three primary justifications for titling (Brasselle, Frédéric, and Jean-Philippe 2002). First, the "assurance effect" implies that a title will provide households with secure tenure which will increase the household's incentives to invest in their dwelling (Jimenez 1984). Second, the "collateralization effect" infers the ability to use a property as collateral and thus gain access to credit markets, making upgrades more affordable (Feder and Nishio 1998). Third, the "realizability effect" lowers the transaction costs of transferring one's property to others (Besley 1995). Willingness to invest in hazard mitigation will increase, if households expect to reap the long term benefits of greater safety and increased home values. In Madhya Pradesh, India, for instance, slum dwellers with titles spend about twice as much on home maintenance and upgrading housing quality compared to other slum dwellers (Lall, Suri, and Deichmann 2006). Property rights are also associated with a higher degree of community participation (Lanjouw and Levy 2002; Lall and others 2004). Community-based hazard risk reduction strategies may therefore more likely succeed in neighborhoods where tenure security is high. But realizing the benefits from titling programs faces numerous institutional constraints, as documented in the literature.

Provide Information. A core task of the urban public sector is the collection of information that is relevant to urban planning and management. This includes producing credible information on hazard risk and making it easily available to all stakeholders. Such information is often produced by private firms as well, but selective disclosure creates information asymmetries that put households at a disadvantage. Data on hazard probabilities and vulnerability of structures and people feed into comprehensive risk assessments. These are based on models that should be considered a public good-transparent and accessible to all. ${ }^{4}$ Such information allows residents to make informed location choices, enables markets to price hazard risk appropriately, encourages the emergence of private insurance markets, and serves as a sound basis for transparent zoning decisions and other land use regulations.

Hazard risk varies across space, so information on hazard event probabilities, exposure, and vulnerability needs to be collected and disseminated spatially. New technologies have made it easier and cheaper to collect geographic data. These include satellite images, with a resolution high enough to replace far more expensive air photos, and global positioning systems that facilitate field data collection. Easy-to-use geographic data browsers (such as Google Earth) make spatial data available to everyone. Most importantly, while hazard mapping has been 
performed for many decades, new technologies allow constant updating of information at relatively low cost. Making these technologies accessible to cities-not only the largest, but also smaller and medium sized cities with limited local capacity—should be a priority for national governments and donors.

Institutionalize Urban Hazard Management. Risk management will be most effective if hazard related tasks are closely integrated with other urban management activities. Several cities have started to institutionalize hazard risk management within their local administrations. Table 1 provides a snapshot of policies from Bogotá, Metro Manila, Istanbul and Seoul. These examples illustrate that there are different models of hazard risk management and that experience varies across countries. A key ingredient is strong institutional capacity at the local level. Yet most developing country cities are severely resource and capacity constrained, while facing a backlog of public investment and continued population growth. These cities will need to invest billions of dollars in public infrastructure and services, as many of them will double in size over the next three decades. Mainstreaming risk reduction in urban planning and management will help to reduce risk, and at a lower cost compared to ex post mitigation.

This also raises the issue of organizing hazard management tasks across levels of government (see for example Demeter, Aysa, and Erkan 2004). As with decentralization more generally, the distribution of administrative, fiscal, and implementation functions will need to be adapted to the size and capacity of each country. Central government institutions provide the legal framework, coordination, and resources that are scarce at the local level, such as technical expertise and financing for large scale investments. Other tasks, especially for preparedness, will require strong local leadership and participation. In the Philippines, for instance, this happens through disaster coordinating councils at regional, provincial, and barangay (local authority) levels. These take advantage of what is most abundant locally: a large and relatively inexpensive labor force with detailed knowledge about local conditions. Institutionalizing the intergovernmental division of responsibilities is a complex task, but it is necessary for effective hazard management.

\section{Costs and Benefits of Large-scale Collective Hazard Mitigation}

Improving urban management to reduce hazard risk is something cities must do to support risk reduction. The decision to invest in larger protective infrastructure is more complex. For instance if parts of a city are at risk of flooding from river overflows or storm surges, large scale infrastructure investments in dams or levees can reduce that risk. Such investments raise several important questions. 
Table 1. Policies and Experiences of Hazard Risk Management (Selected Cities)

\begin{tabular}{|c|c|c|c|c|c|}
\hline City & $\begin{array}{c}\text { No. of local } \\
\text { governments } \\
\text { under } \\
\text { jurisdiction }\end{array}$ & $\begin{array}{l}\text { Legislation for hazard risk } \\
\text { management (DRM) }\end{array}$ & $\begin{array}{c}\text { Key elements of hazard risk } \\
\text { management }\end{array}$ & Stakeholder involvement & Experience \\
\hline
\end{tabular}

- In 1995, a resettlement plan was initiated for informal settlements residing in highrisk zones to relocate

households to safer areas.

\section{Istanbul,}

Turkey
Since 1999, legal reforms in the country provided metropolitan cities greater jurisdictional authority over land and buildings.
- Metropolitan Municipality of Istanbul established AKOM, a $24 / 7$ state of the art disaster coordination system.

- Municipalities increased authority over building construction supervision and compulsory earthquake insurance laws.
The city needs to strengthen enforcement of norms and standards, and improve involvement of local governments. 


\begin{tabular}{|c|c|c|c|c|c|}
\hline $\begin{array}{l}\text { Metro } \\
\text { Manila, } \\
\text { Philippines }\end{array}$ & $\begin{array}{l}17 \text { local } \\
\text { government } \\
\text { units (LGUs) }\end{array}$ & $\begin{array}{l}\text { Apex Organization:Metro } \\
\text { Manila Disaster Coordinating } \\
\text { Council. All LGUs have their } \\
\text { own disaster coordinating } \\
\text { councils. }\end{array}$ & $\begin{array}{l}\text { Each LGU prepares its own } \\
\text { comprehensive land use plan } \\
\text { which is submitted to the } \\
\text { Housing and Land use } \\
\text { Regulation Board for } \\
\text { ratification. }\end{array}$ & n.a. & DRM is focused on response. \\
\hline $\begin{array}{l}\text { Seoul, } \\
\text { South } \\
\text { Korea }\end{array}$ & $\begin{array}{l}25 \text { self- } \\
\text { governing } \\
\text { districts }\end{array}$ & $\begin{array}{l}2001 \text { Comprehensive } \\
\text { Earthquake Prevention Plan. }\end{array}$ & $\begin{array}{l}\text { Requires existing buildings to be } \\
\text { tested against seismic activity } \\
\text { based on earthquake resistant } \\
\text { design standards from } 1999 \text { to } \\
2005 \text {. }\end{array}$ & $\begin{array}{l}2001 \text { action plan } \\
\text { involving Seoul Red } \\
\text { Cross and incorporates a } \\
\text { public-private } \\
\text { partnership for local } \\
\text { earthquake management } \\
\text { plan. }\end{array}$ & n.a. \\
\hline
\end{tabular}


Do the Benefits Justify the Costs?. Investments in large scale infrastructure compete with other demands for scarce resources in developing country cities. The cost-benefit calculation largely depends on the value of land. In dynamically growing cities, where land is scarce, large scale investments to make land habitable or reduce significant risk may well be justified. An analogy is the large scale land reclamation in cities such as Hong Kong, Singapore, or around the urban core of the Netherlands. Limited alternative expansion options in the vicinity of high economic density raise the value of land significantly. This shifts the costbenefit ratio in favor of large protective investments. A strict test is whether a developer would, in principle, be willing to pay a price for the reclaimed or protected land that reflects the cost of the intervention.

The viability of large scale disaster mitigation infrastructure will be very different in cities with a stagnant economy and little or no population growth. Declining cities are a phenomenon of mature economies and transition economies, such as former socialist countries with demographic decline or strong geographic shifts in economic and population centers (Pallagst 2008). Examples are found in Central and Eastern Europe but also parts of Scandinavia and the Mediterranean, as well as the old industrial core of the U.S. Midwest. Over time, given demographic trends in many middle income countries, "shrinking cities" may also occur in some of today's emerging economies, for instance in East Asia.

The best known example in a natural disaster context is New Orleans. Public investments in the wake of Hurricane Katrina in 2005 have sparked a vigorous debate on the role of large scale protective investments to encourage the rebuilding of New Orleans within the pre-Katrina city limits. It is estimated that $\$ 200$ billion of federal money will be used to rebuild the city. Some have provocatively suggested providing residents in the city's flood-prone neighborhoods with checks or vouchers instead, and letting them make their own decisions about how to spend that money-including the decision about whether to relocate (Glaeser 2005). The choice is between spending $\$ 200$ billion on infrastructure versus giving each resident a check for more than $\$ 200,000$ - in a place where annual per capita income is less than $\$ 20,000$. From an urban economics perspective, it may not be the best use of scarce funds to invest in rebuilding large scale protective infrastructure in New Orleans, a city in decline that reached its peak of economic importance in $1840 .{ }^{5}$ The calculation for a dynamically growing city may be very different.

Are there Adverse Impacts on Poor Population Groups?. Large scale protective infrastructure turns undesirable land-often the only space available for the poorinto coveted real estate. Development of this land may well displace poor residents who will have no place to go but other risk-prone parts of a city or places that are far from economic opportunity. These displacements need to be anticipated by 
requiring set-asides for low income households, designing proper compensation mechanisms, socially responsible resettlement schemes, or alternative housing options with good accessibility to jobs and services. Planning protective infrastructure must therefore be embedded in broader urban development planning. The costs of mitigating distributional impacts need to be considered in the overall cost-benefit analysis. This may shift the balance in favor of smaller scale risk reduction strategies such as early warning or mitigation at the individual level.

Will the Investment Be Climate-proof?. Engineering designs for hazard resistant structures typically follow a standardized risk based approach. For instance according to the American Society of Civil Engineers, in the United States major dams are designed so that the probability of a failure causing more than a thousand fatalities is less than once every 100,000 to 1 million years. Estimating these risks is difficult, especially where the geophysical baseline information is limited. Furthermore the level of risk may not be static. With climate change, floods, or storm surges return periods may shorten considerably during the life span of long-lived infrastructure. What was once a 1 in a 500-year event (or a 1 in 10 chance every 50 years), may become a 1 in a 250 or a 1 in a 100-year event. Making structures climate resilient requires designs with a high margin of safety. Storm surge protection in the Netherlands is designed to withstand events with a 10,000-year return period. This increases costs. But the alternative is to face higher than expected risks after protective investments have increased exposure by encouraging people and firms to move into harm's way.

Do Alternative Mitigation Strategies Exist?. Some hazard risk is made more severe by human interference in natural systems in the vicinity of urban areas. Increased urban flooding — for instance in South and Southeast Asia—is often attributed to deforestation in upper watersheds. But many scientists believe that the conversion of wetlands to urban use has contributed, perhaps more significantly than was thought, to more frequent floods (Bonell and Bruijnzeel 2004). Draining wetlands reduces the absorption capacity of soils, removing the natural buffer function of these areas. Compared to costly flood control infrastructure, restoring the ability of the land to regulate water flow may be a more cost effective risk reduction strategy with additional ecological benefits.

Large scale protective infrastructure will sometimes be justified on economic grounds where land is scarce and valuable, financial resources are available, no lower cost options exist, and environmental and social impacts can be minimized. But, as the discussion in the previous paragraphs showed, the bar must be set fairly high. 


\section{Encouraging Individual Level Risk Mitigation}

As discussed earlier, the evidence from hedonic analysis suggests that a hazardous location and vulnerable building quality reduce housing prices. Yet, even in highrisk cities and neighborhoods, individual level mitigation efforts are often scarce. ${ }^{6}$ Economic and behavioral reasons provide some possible explanations.

Why do individuals often not invest in hazard mitigation?. Limited mitigation in private buildings may be related to home ownership in cities. In rural areas, most people live in dwelling units owned by the household. The person responsible for the strength of the structure is also the person bearing the consequences if the structure fails. In urban areas, many multiunit apartment buildings are owned by landlords who do not live in them, so the person responsible for the structural integrity of the building is not at major risk of being injured or killed when the structure collapses. The relationship between landlords and tenants (that is renters) of residential buildings in urban areas exhibits the properties of the wellknown principal-agent (PA) problem in information economics. ${ }^{7}$ Not only are the objective functions of the two parties different from each other, but their information sets are likely very different as well.

For a nonresident landlord, the consequences of poor construction or lack of retrofitting are related primarily to physical damage to the building. The potential cost of human life or destruction of tenants' property may not be incorporated fully in the landlord's investment decision, especially when criminal prosecution for negligence in construction or maintenance is unlikely. Traditional cost-benefit analysis for retrofitting investment which does not incorporate the expected loss of tenants' lives shows that potential building damage alone is typically not sufficient to justify investment on the part of building owners (Ghesquiere, Jamin, and Mahul 2006).

An expectation of government aid in the event of a natural disaster further dampens the perceived benefits of retrofitting for the landlord (OECD 2004). Studies have also shown that house owners may be making decisions based not on an expected utility model but rather using simplified heuristics that do not fully incorporate the probability of disaster, even when it is perfectly observed (Kunreuther and Kleffner 1992). Finally there is often a high level of mistrust between home owners and contractors, who may provide substandard building services. Without independent assessment as to whether a retrofitting solution is adequate and cost-effective, landlords may not want to risk scarce capital.

In many developing countries, building code design, regulation, and enforcement are inadequate, if they exist at all. This lack of regulation, often exacerbated by widespread corruption (see for example Escaleras, Anbarci, and Register 
2007), diminishes the potential legal consequences for the landlord, while making it harder for tenants to pursue legal action. Disasters are often seen as "acts of God," and only gross negligence is prosecuted. In countries where legal institutions are weak, prosecution in any instance may not be feasible (Jain 2005).

On the other hand, the benefits from retrofitting may be high for those tenants who expect to occupy the building long-term-for instance, where rent control makes staying very attractive or where housing markets are illiquid and prices are high relative to rents. Why do long-term tenants then not directly finance, or otherwise initiate, retrofitting in their places of residence? The simplest explanation is that individuals are not fully aware of hazard risk, which is a function both of the probability of a hazard event such as an earthquake and of the vulnerability of their dwelling units. This risk can vary significantly even within a given neighborhood of an earthquake-prone city (Nakagawa, Saito, and Yamaga 2007). The behavioral economics literature also shows that, especially for rare events like large-scale earthquakes, probabilities are often not accurately assessed. Individuals adhere to a "selective fatalism," choosing to downscale the importance or likelihood of events over which they perceive having little or no control (Sunstein 1998).

Since infrastructure investment for risk mitigation is likely to accrue benefits only in the long term on average, individuals' subjective discount rates over time also play a potentially important role in evaluating the costs and benefits of such investment (Kenny 2009). Because of the multitude of risks often faced by individuals in resource-poor countries-such as higher mortality from disease or traffic accidents-discount rates may be higher than in industrialized countries, thus creating a high opportunity cost of investments that yield payoffs only in the long run or not at all.

But even where the risk is generally known, there are a number of possible reasons for tenants' complacency. First, financial constraints, including low liquidity and low access to credit, can be significant barriers to investment. Access to credit is particularly low where owner-residents or landlords have only de facto, not de jure, tenancy, so they cannot use their dwelling as collateral. Second, tenants often do not have the legal authority to make changes to their building's structure. Third, appropriate retrofitting procedures involve structural changes to the entire residential structure, not to individual apartments. Anbarci, Escaleras, and Register (2005) show that collective action problems, like the decision of a building's tenants to invest in retrofitting, are exacerbated by inequality: heterogeneous agents bargaining for collective action may not be able to agree on an adequate distribution of costs, inducing a noncooperative equilibrium in which each individual self-insures or does not insure at all. 
Policies to Increase Private Mitigation Efforts. Strengthening building codes and effective enforcement have reduced the number of vulnerable dwelling units in countries such as Japan or the United States. Hazard insurance further protects against some of the consequences of a disaster. ${ }^{8}$ But high insurance coverage can also reduce the incentive to implement loss reduction measures (Kunreuther and Kleffner 1992). Insurance covers the loss of property, but earthquakes and other hazards can also cause high mortality. Governments therefore frequently mandate the implementation of cost-effective mitigation. Insurance premiums should then reflect the lower risk. But in environments with weak institutions and enforcement, regulation by itself is not sufficient, and insurance is typically unavailable in poorer countries because of limited affordability as well as inadequate information about hazard probabilities and vulnerability.

Appropriate policies to increase sensible mitigation measures in cities with weak institutions should try to align the objectives and information sets of tenants and landlords. Using the principal-agent framework, policies will differ in the degree of government intervention in markets. The least interventionist policy is information disclosure to both tenants and landlords. This information has two components: hazard probability and building vulnerability. First, in the context of earthquake risk, for instance, tenants must be made aware of the risks of living in buildings close to active fault lines and on vulnerable soils. This requires investment in geological surveys and seismic monitoring technology and dissemination of the resulting information as a public good.

The assessment of building quality is more complex. This requires an engineering assessment of each structure. This is costly, so the question is whether the landlord, who will likely pass on the cost to tenants, or the government should cover the cost. A compromise is where an initial public engineering inspection yields a simple vulnerability score. If the score is above a certain threshold, the building owner is required to obtain a more thorough inspection that proves the building's integrity. ${ }^{9}$ Improved information could also mitigate the problem of selective fatalism discussed earlier. It will help tenants make the link between housing choice and hazard risk. Since price is often the most easily processed signal of underlying quality, public disclosure of idiosyncratic earthquake risk could generate a rental market with an informative price gradient (Brookshire and others 1985).

With better information landlords may also revise their cost-benefit calculations. A landlord's decision not to act on the improved information could generate a social cost on such negligence in the form of public shaming. This added cost could tip the balance in favor of mitigation investments. Such strategies have been implemented successfully in the control of industrial pollution through public disclosure of emission levels of firms using a simple rating system 
(Wheeler 2000). The driving forces behind these efforts have been national environmental agencies as well as non-governmental organizations.

Another important source of inefficiency through PA interaction is informational asymmetry. Landlords will often have more information than their tenants about hazard risk and building safety. Landlords have little incentive to reveal this information to tenants. Policy intervention in this case should be aimed at reducing the extent of asymmetry by making the same information available to both parties. One possibility is to introduce monitoring agreements into rental contracts, although the effectiveness of such agreements would need to be proven in practice. Risk information disclosed through these agreements enables potential tenants to judge the extent of retrofitting or sound construction accurately. Mandating such agreements would exert pressure on landlords, through the market mechanism, to engage in retrofitting investment. The cost of monitoring - hiring trained engineers to survey and test the construction of buildingscan be borne by some combination of the government, landlords, and tenants. The success of this approach will critically depend on avoiding rent seeking by monitors.

Finally, another strategy is direct support to landlords to engage in retrofitting investment, for instance in the form of subsidized credit or tax breaks, or direct penalties for not doing so. This policy involves significantly more government intervention. The economic literature on optimal contracting methods for different types of principal-agent interaction can provide some guidance. For example Hiriart and Martimort (2006) show that in the context of regulation of environmentally risky firms, mandating an extension of liability for environmental risk to stakeholders (principals) in endogenously formed contracts can be welfareimproving for both parties. The concept of extended liability could potentially be adapted to the landlord-tenant relationship in the disaster mitigation case: if landlords were held liable for the avoidable consequences of hazard events that affect their tenants, their cost-benefit calculations would likely change dramatically.

Gawande and Bohara (2005), who examine law enforcement of oil spills involving U.S. flag tank vessels, find that the optimal contract is a mixture of ex ante incentives and ex post penalties. This carrot-and-stick brand of contracting could be beneficial in the disaster mitigation case as well. Giving landlords monetary incentives to retrofit, and threatening penalties in the case when they have not, could be an effective combination.

Using incentives or penalties to align retrofitting objectives may be most appropriate for the construction of new urban residential buildings in fast growing cities. There are significant opportunities to influence construction quality and avoid past mistakes. Some form of direct support, paired with public disclosure agreements of the sort discussed above, could provide significant incentives to 
landlords to construct buildings capable of withstanding hazard impacts. As with all types of subsidies for hazard risk reduction, however, these need to be carefully designed to avoid moral hazard that can reduce incentives for autonomous risk reduction efforts or encourage building in areas of clearly delineated high riskas is often the case with subsidized risk transfer, such as flood insurance.

\section{Summary}

Natural hazard risk in urban areas is large and increasing. It is largely driven by rising exposure of population and assets and may increase further with climate change. Even in the most hazard-prone cities, disaster risk is unlikely to reduce population growth, because the economic premium from agglomeration economies and the amenity value of large cities dominate the location decisions of firms and people (World Bank 2008). So eliminating risk by avoiding cities in hazard zones is not usually an option. Instead urban hazard risk needs to be managed and reduced to the extent possible. Our discussion of economic aspects of urban hazard risk leads to three main implications.

\section{All Cities Are Not Equal}

First, the cope-mitigate-transfer framework of risk management (Ehrlich and Becker 1972) can also guide policies for different types and sizes of cities. Reducing urban hazard risk through large scale mitigation measures must carefully consider urban dynamics: it will often be justified in rapidly urbanizing places that are attracting skilled workers and private investment, where land is scarce and fiscal capacity is sufficient; but it is unlikely to have sufficient benefits in stagnating or declining cities. This applies to ex ante investments as much as to the decision to rebuild. Sometimes, rather than "build back better" (see for example Kennedy and others 2008), the preferred strategy is "better build elsewhere."

This yields a simple typology (table 2). For the largest and most dynamic cities we expect that the benefits from agglomeration economies outweigh greater risk, especially when the probabilities are relatively small for any reasonable time period (as in the case of earthquake risk). Risk mitigation (for example retrofitting buildings) and risk transfer (for example insurance) will be the main responses, especially where credible information on risk is available. In secondary or intermediate cities, people are more likely to move to more dynamic cities or to invest in mitigation. Insurance is less likely to be an option because persistent information failures and smaller size mean that there is no transparent and large enough market. For small, stagnant, or declining cities, moving, coping, or 
Table 2. Typology of Cities

\begin{tabular}{llll}
\hline City type & $\begin{array}{c}\text { Cope or } \\
\text { move }\end{array}$ & Mitigate & Transfer risk or insure \\
\hline Advanced urbanizers "superstars" & $\mathrm{X}$ & $\checkmark$ & $\checkmark$ \\
Secondary or intermediate cities & $\checkmark$ & $\checkmark$ & $\begin{array}{c}\text { X(information failures, market } \\
\text { size) }\end{array}$ \\
$\begin{array}{l}\text { Market towns or incipient } \\
\text { urbanization }\end{array}$ & $\checkmark$ & $\begin{array}{c}\text { X (costs exceed } \\
\text { benefits) }\end{array}$ & $\mathrm{X}$ \\
\hline
\end{tabular}

low-cost locally initiated mitigation efforts may be the main response. Significant investment in large scale collective mitigation is unlikely to be cost effective and insurance markets will not extend to the smallest towns.

\section{Quality of Urban Management Is Key}

The second major conclusion is that hazard risk reduction in cities requires, first and foremost, good general urban management. It needs to be seen as an integral part of urban planning and management, not as a separate activity. Urban disasters are frequently the consequence of poor urban management. Three aspects are particularly important: Most importantly, hazard proofing new urban infrastructure should be standard procedure, but is frequently ignored. This includes adherence to structural engineering standards for public buildings, but also sizing of drainage systems for peak events or developing steeply sloped land without increasing the probability of landslides.

Secondly, maintenance of infrastructure and good basic service provision reduce the impacts of hazard events and prevent further indirect damages. ${ }^{10}$ Poor service delivery not only has adverse direct effects on household welfare, it can also convert everyday hazards into disasters (Bull-Kamanga and others 2003). For instance where drainage networks are poorly maintained, even moderate floods can cause deaths from waterborne diseases and cross-contamination between water and sewer lines. Where roads on steep terrain are not kept in good condition, they can increase erosion and landslide risk. These "institutional" efforts to achieve minimum standards in service delivery should form the bedrock of hazard risk reduction strategies.

Finally, land use management, in particular zoning, needs to prevent the settlement of the most hazardous areas. Poor people often bear a disproportionate burden of hazard risk because land scarcity forces them to "sort" into informal settlements or low rent dwellings in hazard prone areas such as flood plains or steeply sloped land. For instance in New Orleans: "After [Hurricane] Betsy [in 1965] highlighted the differentials of flood risk, the middle classes moved away 
from the eastern part of the city and the lowest lying districts became increasingly unimproved rental properties - the preserve of low income and elderly residents" (Muir-Wood 2008). While enforcement of zoning laws may limit development in hazardous locations, it can cut poor people off from labor market opportunities by forcing them onto cheaper land far from the city center. Complementary demand side policies, such as reforming land use regulations for higher density growth, rent vouchers, or improving access to housing finance, can help informal sector residents move into better quality dwellings. Investments in affordable transport integrate lower-cost residential areas and expand a city's economic reach-creating a larger integrated labor market. With good transport services, households do not need to locate in informal settlements in hazard-prone parts of the city. Local governments must develop the capacity to balance the need for flexible land use management with enforcement of zoning and building standards.

\section{Credible Risk-related Information Must Be a Priority}

Generating and disseminating hazard information is perhaps the least distortionary urban hazard management policy. Where credible information on the distribution of geophysical hazard risk and the vulnerability of structures exists, empirical evidence suggests that hazard risk is capitalized into prices for residential properties and office space. Informed residents can choose between moving to less risky locations, investing in mitigation in situ, or transferring risk through insurance where available. In fact credible and public information provides a basis for the emergence of efficient private insurance markets. Where risk assessments are generated by the insurer and not disclosed, information asymmetries put residents at a disadvantage. Finally, public risk information serves as a sound basis for transparent and least distortionary zoning decisions and other land use restrictions. Unfortunately encouraging data sharing, even when data generation was funded with public resources, is not a trivial task. Public agencies often see data as a strategic or marketable asset rather than as a public good whose wide and inexpensive distribution increases overall welfare.

Public policies should facilitate the development of market based instruments for the better managing of hazard risk, provide the right regulatory environment, and selectively intervene where clearly defined social and environmental externalities exist. Common institutions that allocate property rights, manage land use, monitor zoning compliance, and disseminate credible information on hazard risk are the most important instruments for balancing gains from economic density with risk from natural hazards. As many cities in developing countries will double in size over the next few decades, there is an opportunity to manage this growth to minimize hazard risk. This will challenge management capacity at all 
levels of government-from urban development ministries to small town mayors. But the payoffs in saved lives and avoided damages will be high.

\section{Notes}

Somik V. Lall is in the World Bank's Finance, Economics and Urban Department; slall1@worldbank. org. Uwe Deichmann is in the Energy and Environment Team of the World Bank's Development Research Group. A previous version of this article was prepared as a background paper for the joint World Bank-UN Assessment on the Economics of Disaster Risk Reduction (World Bank 2010). Funding from the Global Facility for Disaster Reduction and Recovery is gratefully acknowledged. The authors thank Achyuta Adhvaryu, Laura Atuesta, Henrike Brecht, Hyoung Gun Wang, Pascal Peduzzi, Luis Yamin, and Jun Wan for contributions to portions of this article. Apurva Sanghi, S. Ramachandran, Michael Toman, seminar participants at the World Bank, three anonymous reviewers and this journal's editor provided helpful comments. The findings, interpretations, and conclusions expressed are entirely those of the authors. They do not represent the views of the World Bank, its Executive Directors, or the countries they represent.

1. Vulnerability in this definition includes factors that affect the likelihood of damages during the event and factors that allow communities to recover from those impacts (coping capacity). While both aspects of vulnerability are important, this paper focuses mainly on ex ante risk reduction, for instance measures that reduce the vulnerability of buildings to damages from earthquakes or wind storms. The second aspect is most relevant for post-disaster response and recovery and includes policies such as first responder services, cash transfer programs, and strengthening social insurance and social protection (see Vakis 2006). Note that a more comprehensive social risk management framework has been the basis for the World Bank's social protection portfolio (World Bank 2001). While not specific to urban disaster risk, many of its elements have become integral to natural hazard risk reduction efforts.

2. (http://uk.reuters.com/article/homepageCrisis/idUKBOM301508._CH_.242020080528).

3. To prevent settlement of steep lands in Bogotá, the city government establishes communal facilities in those areas, such as public parks or cemeteries. Local residents then ensure that no encroachment occurs, as they benefit from these amenities (Francis Ghesquieres, personal communication).

4. Risk modeling companies typically use proprietary models and require nondisclosure agreements with licensees (Murnane 2007).

5. The Civil War and the relative decline of water-based transportation relative to rail caused the city to lose ground, relative to northern cities, through much of the nineteenth century. New Orleans's population peaked at 627,000 residents in 1960 and began to decline following Hurricane Betsy in 1965 to 485,000 residents in 2000 (Glaeser 2005).

6. Richard Sharpe (Earthquake Engineering New Zealand) reported on evidence from Istanbul that many areas with the highest potential ground acceleration in the likely event of a future earthquake are occupied by five-floor apartment buildings. Inspection of a sample of these buildings suggests that most would not be able to withstand a major earthquake (51 percent were at high risk, 28 percent at very high risk). Building collapse will likely lead to high mortality. Yet, structural retrofitting of these buildings is extremely rare, at costs of external retrofitting solutions of 19 percent of reconstruction costs (Sharpe 2008).

7. See for example Laffont and Martimort (2002); the discussion of the principal-agent problem is based on Adhvaryu and Deichmann (2009).

8. We do not cover insurance issues in detail in this paper, because there are relatively few aspects that are specific to urban settings. World Bank (2010) provides a general overview of the economics of hazard insurance. 
9. New Zealand, a country with high seismic activity, uses this approach.

10. The poor record on infrastructure maintenance has been highlighted by Estache and Fay (2007), among others. At 4 percent of GDP, estimates of required maintenance expenditures equal those required for new infrastructure investment.

\section{References}

The word processed describes informally reproduced works that may not be commonly available through libraries.

Adhvaryu, Achyuta, and Uwe Deichmann. 2009. "Information Economics Aspects of Risk Reduction in Urban Settings." Development Research Group, World Bank, processed.

Anbarci, Nejat, Monica Escaleras, and Charles Register. 2005. "Earthquake Fatalities: The Interaction of Nature and Political Economy." Journal of Public Economics, 89:1907-33.

Atuesta, Laura, Uwe Deichmann, Somik V. Lall, and Luis Yamin. Forthcoming. "Is Hazard Risk Capitalized into Housing Prices? Evidence from Bogotá." World Bank, processed.

Besley, T. 1995. "Property Rights and Investment Incentives: Theory and Evidence from Ghana." Journal of Political Economy, 103(5): 903-37.

Bin, Okmyung, and Stephen Polasky. 2004. "Effects of Flood Hazards on Property Values: Evidence Before and After Hurricane Floyd." Land Economics, 80(4): 490-500.

Bin, O., J. Brown Kruse, and C.E. Landry. 2008. "Flood Hazards, Insurance Rates, and Amenities: Evidence from the Coastal Housing Market." Journal of Risk and Insurance, 75(1): 63-82.

Bonell, M., and L.A. Bruijnzeel. 2004. Forests, Water and People in the Humid Tropics. Cambridge, UK: Cambridge University Press.

Bowen, William. 2002. "An Analytical Review of Environmental Justice Research: What Do We Really Know?" Journal of Environmental Management, 29(1): 3-15.

Brasselle, G. Frédéric, and P. Jean-Philippe. 2002. "Land Tenure Security and Investment Incentives: Puzzling Evidence from Burkina Faso." Journal of Development Economics, 67:373-418.

Brookshire, David, Mark Thayer, John Tschirhart, and William Schulze. 1985. "A Test of the Expected Utility Model: Evidence from Earthquake Risks." Journal of Political Economy, 93(2): 369-89.

Bull-Kamanga, L., K. Diagne, A. Lavell, E. Leon, F. Lerise, H. MacGregor, A. Maskrey, M. Meshack, M. Pelling, H. Reid, D. Satterthwaite, J. Songsore, K. Westgate, and A. Yitambe. 2003. "From Everyday Hazards to Disasters: The Accumulation of Risk in Urban Areas." Environment and Urbanization, 15(1): 193-203.

Demeter, Katalin, Guener Aysa, and Nihal Ekin Erkan. 2004. "The Role of Local Governments in Reducing the Risk of Disasters.” World Bank Institute, Washington, DC. Processed.

Dilley, Maxx, Robert S. Chen, Uwe Deichmann, Art L. Lerner-Lam, and Margaret Arnold. 2005. Natural Disaster Hotspots: A Global Risk Analysis. Washington, DC: World Bank and Columbia University.

Duranton, Gilles, and Diego Puga. 2004. "Microfoundations of Urban Agglomeration Economies." In Vernon Henderson, and Jacques François Thisse, eds., Handbook of Regional and Urban Economics. Vol. 4. Amsterdam: North Holland, 2063-117.

Ehrlich, Isaac, and Gary S. Becker. 1972. "Market Insurance, Self-Insurance, and Self-Protection." The Journal of Political Economy, 80(4): 623-48. 
Escaleras, Monica, Nejat Anbarci, and Charles Register. 2007. "Public Sector Corruption and Major Earthquakes: A Potentially Deadly Interaction.” Public Choice, 123(1): 209-30.

Estache, Antonio, and Marianne Fay. 2007. "Current Debates on Infrastructure Policy." Paper Prepared for the Growth Commission, The World Bank, Washington DC.

Fay, Marianne, Francis Ghesquiere, and Tova Solo. 2003. "Natural Disasters and the Urban Poor", En Breve, October, 32, Latin America and Caribbean Region, World Bank.

Fay, Marianne, J. Luis Guasch, Rosanna Nitti, and Soumya Chattopadhyay. 2001. "The Anatomy of a Slum: The Ozama Barrios in Santo Domingo." Processed, Latin America and Caribbean Region, World Bank.

Feder, G., and A. Nishio. 1998. "The Benefits of Land Registration and Titling: Economic and Social Perspectives," Land Use Policy, 15(1): 24-44.

Gawande, Kishore, and Alok Bohara. 2005. "Agency Problems in Law Enforcement: Theory and Application to the U.S. Coast Guard." Management Science, 51(11): 1593-609.

Ghesquiere, Francis, Luis Jamin, and Olivier Mahul. 2006. "Earthquake Vulnerability Reduction Program in Columbia: A Probabilistic Cost-benefit Analysis." World Bank Policy Research Working Paper 3939.

Glaeser, Edward L. 2005. "Should the Government Rebuild New Orleans, or Just Give Residents Checks?” Economists' Voice, 2(4): . http://www.bepress.com/ev/vol2/iss4/art4

Gomez-Ibañez, J., and F. Ruiz Nuñez (2006), Inefficient Cities. Harvard University, Processed.

Henderson, J. Vernon (2003), The Urbanization Process and Economic Growth: The So-What Question, Journal of Economic Growth, 8, 47-71.

Hiriart, Yolande, and David Martimort (2006), The Benefits of Extended Liability, RAND Journal of Economics, vol. 37, no. 3: 562-582.

ISDR (International Strategy for Disaster Reduction) (2009), Risk and poverty in a changing climate, 2009 Global Assessment Report on Disaster Risk Reduction, United Nations, Geneva.

Jain, Sudhir. 2005. “The Indian Earthquake Problem.” Current Science, 89(9): 1464-6.

Jimenez, Emmanuel. 1984. "Tenure Security and Urban Squatting." The Review of Economics and Statistics, 66(4): 556-67.

Kahn, Matthew E. 2005. "The Death Toll from Natural Disasters: The Role of Income, Geography and Institutions, Review of Economics and Statistics, 87(2): 271-84.

Kennedy, Jim, Joseph Ashmore, Elizabeth Babister, and Ilan Kelman. 2008. "The Meaning of Build Back Better: Evidence from Post-Tsunami Aceh and Sri Lanka." Journal of Contingencies and Crisis Management, 16(1): 24-36.

Kenny, Charles. 2009. "Why Do People Die in Earthquakes? The Costs, Benefits and Institutions of Disaster Risk in Developing Countries.” World Bank Policy Research Working Paper 4823, Development Research Group, World Bank.

Kunreuther, Howard, and Anne E. Kleffner. 1992. "Should Earthquake Mitigation Measures Be Voluntary or Required?" Journal of Regulatory Economics, 4:321-33.

Kunreuther, Howard, and Richard J. Roth. 1998. Paying the Price: The Status and Role of Insurance Against Natural Disasters in the United States. Washington, D.C.: Joseph Henry Press.

Laffont, Jean-Jacques, and David Martimort. 2002. The Theory of Incentives: The Principal-Agent Model. Princeton, NJ: Princeton University Press.

Lall, Somik V., A. Suri, and Uwe Deichmann. 2006. "Household Savings and Residential Mobility in Informal Settlements in Bhopal India." Urban Studies, 43(7): 1-15.

Lall, Somik V., Mattias Lundberg, and Zmarak Shalizi. 2008. "Implications of Alternate Policies on Welfare of Slum Dwellers: Evidence from Pune, India." Journal of Urban Economics, 63:56-73. 
Lall, Somik, Uwe Deichmann, Mattias Lundberg, and Nazmul Chaudhury. 2004. "Tenure, Diversity, and Commitment: Community Participation for Urban Service Provision." Journal of Development Studies, 40(3): 1-26.

Lanjouw, Jean O., and Philip I. Levy. 2002. "Untitled: A Study of Formal and Informal Property Rights in Urban Ecuador." The Economic Journal, 112(482): 986-1019.

McGranahan, Gordon, Deborah Balk, and Bridget Anderson. 2007. "The Rising Tide: Assessing the Risks of Climate Change and Human Settlements in Low Elevation Coastal Zones." Environment and Urbanization, 19(1): 17-37.

Montgomery, Mark R. 2009. "Book Review of World Development Report 2009: Reshaping Economic Geography." Population and Development Review, 35(1): 197-208.

Muir-Wood, Robert. 2007. “Climate Change, Insurance and Development." Presentation at the World Bank, December 3.

Murnane, Robert J. 2007. "New Directions in Catastrophe Risk Models." Presentation at the World Bank, October 9.

Nakagawa, Masayuki, Makoto Saito, and Hisaka Yamaga. 2007. "Earthquake Risk and Housing Rents: Evidence from the Tokyo Metropolitan Area." Regional Science and Urban Economics, 37: 87-99.

OECD. 2004. Large Scale Disasters: Lessons Learned. Paris: Organisation for Economic Co-operation and Development.

Onder, Zeynep, Vedia Dokmeci, and Berna Keskin. 2004. "The Impact of Public Perception of Earthquake Risk on Istanbul's Housing Market.” Journal of Real Estate Literature, 12(2):181-194.

Pallagst, Karina. 2008. "Shrinking Cities: Planning Challenges from an International Perspective." In Cities Growing Smaller. Steve Rugare, and Terry Schwarz(editors), Cleveland: Kent State University, Cleveland Urban Design Collaborative, 5-16.

Pelling, M. 2003. The Vulnerability of Cities: Natural Disasters and Urban Resilience. London: Earthscan.

Rosen, S. 1974. "Hedonic Prices and Implicit Markets: Product Differentiation in Pure Competition." Journal of Political Economy, 82(1): 34-55.

Rosenthal, Stuart S., and William C. Strange. 2004. "Evidence on the Nature and Sources of Agglomeration Economies." In J.V. Henderson, and J.-F. Thisse, eds., Handbook of Urban And Regional Economics, Vol. 4. Amsterdam: North Holland.

Sharpe, R. 2008. "Natural Hazard New Zealand. Disaster Risk Management.” Presentation at the World Bank, 22 September.

Small, Christopher, and Terry Naumann. 2001. "The Global Distribution of Human Population and Recent Volcanism." Global Environmental Change Part B: Environmental Hazards, 3(3-4): 93-109.

Smith, Kerry, V. Jared, C. Carbone, Jaren C. Pope, Daniel G. Hallstrom, and Michael E. Darden. 2006. "Adjusting to Natural Disasters." Journal of Risk and Uncertainty, 33:37-54.

Sunstein, Cass. 1998. "Selective Fatalism." Journal of Legal Studies, XXVII:799-823.

UN. 2008. World Urbanization Prospects 2007 Revision. New York: United Nations Population Division.

Vakis, Renos. 2006. "Complementing Natural Disasters Management: The Role of Social Protection.” SP Discussion Paper 0543, World Bank, Washington, DC.

Wang, Hyoung, Marisela Montoliu, The Geoville Group, Ndèye Fatou, and D. Gueye. 2009. "Preparing to Manage Natural Hazards and Climate Change Risks in Dakar, Senegal." Finance, Economics and Urban Department, World Bank, Washington, DC. Processed. 
Wheeler, David. 2000. Greening Industry: New Roles for Communities, Markets, and Governments. World Bank Policy Research Report. Oxford: Oxford University Press.

Willis, Kenneth, and Ali Asgary. 1997. "The Impact of Earthquake Risk on Housing Markets: Evidence from Tehran Real Estate Agents." Journal of Housing Research, 8(1): 125-36.

World Bank. 2001. Social Protection Strategy: From Safety Nets to Springboards. Washington, DC: Human Development Network.

2005. "Dhaka: Improving Living Conditions for the Urban Poor.” Finance, Economics and Urban Department, World Bank, Washington, DC, processed.

2008. World Development Report 2009: Reshaping Economic Geography. Washington, DC: World Bank.

2009. "Current and Future Estimates of Exposure to Natural Hazards in the World's Large Cities." Background analysis for the Economics of Disaster Risk Reduction Report, Washington, DC.

2010. Natural Hazards, Unnatural Disasters: The Economics of Effective Prevention. Washington, DC: World Bank.

Zhuang, Juzhong, Zhihong Liang, Tun Lin, and Franklin De Guzman. 2007. "Theory and Practice in the Choice of Social Discount Rate for Cost-benefit Analysis: A Survey.” ERD Working Paper 94, Asian Development Bank, Manila. 